\title{
LETTERS
}

\section{The Crucible of Physician Performance Reports}

To the Editors:-We all agree that inaccurate physician performance data confuses and obfuscates. It wreaks havoc with reputations, instigates work for internists like Dr. Woo and breeds cynicism about performance reports.

These problems are not new. Ten years ago similar reports inaccurately attributed patients to a practice, omitted key data bases while collecting administrative data and used flawed diagnostic algorithms to categorize patients. ${ }^{1}$ These errors were intrinsic to the report card generation and greatly limited the report cards ability to measure true performance differences between physicians. Nor are these problems limited to health care. New York City teachers decried their reports cards which evaluated student progress and teaching skills of teachers on maternity leaves. ${ }^{2}$

I wonder if Dr. Woo uncovered systemic problems in how his report card was created. Such errors might have affected many of his California physician colleagues. His work is important as the enthusiasm for report cards on individual physicians ${ }^{3}$ has far exceeded their precision and reliability, particularly as sample sizes rarely conform to statistical standards. ${ }^{4}$
Rachel Sorokin, MD, FACP, Chief Patient Safety and Buality Officer, Thomas Jefferson University Hospital, Philadelphia, PA, USA (e-mail: rachel.sorokin@jefferson.edu).

\section{REFERENCES}

1. Sorokin R. Alternate Explanations for Poor Report Card Performance. Eff Clin Pract. 2000;3:25-30.

2. Otterman S. Hurdles Emerge in Rising Effort to Rate Teachers New York Times. Dec 27, 2010 page Al. Also at http://www.nytimes.com/2010/ 12/27/myregion/27teachers.html?_r=1 accessed Feb. 8, 2011

3. Terry K. Physician report cards: Help, ho-hum or horror? Modern Medicine. July 21, 2006 at http://www.modernmedicine.com/modern medicine/article/articleDetail.jsp?id=359028 accessed Feb. 8, 2011

4. Hofer TP, Hayward RA, Greenfield S, Wagner EH, Kaplan SH, Manning WG. The unreliability of individual physicians "report cards" for assessing the costs and quality of care of a chronic disease. JAMA. 1999;281:2098-2105.

J Gen Intern Med 26(6):573

DOI: $10.1007 / \mathrm{s} 11606-011-1690-0$

(C) Society of General Internal Medicine 2011

Woo, HE. The Crucible of Physician Performance Reports. J Gen Intern Med 26:226-7

Published online March 30, 2011 